\title{
Effect of Nano Materials on Performance Characteristics of High Strength Self Compacting Concrete
}

\author{
Boppana Narendra Kumar a, ${ }^{*}$, B. Abhilash a, CH. Naveen Kumar a, S. Pavan a \\ a Department of Civil Engineering, VNR VJIET, Telangana-500090, Hyderabad, India \\ *Corresponding author Email: narendrakumar b@vnrvjiet.in \\ DOI: https://doi.org/10.34256/nnxt2123 \\ Received: 20-06-2021; Revised: 28-06-2020; Accepted: 29-06-2021; Published: 30-06-2021
}

Abstract: In today's fast-growing world, it is critical to utilize green, sustainable, and resilient materials keeping the impact of carbon in mind. The use of Nanomaterials has evolved to improve the performance characteristics of cement composites. As a result, Graphene Oxide (G.O) was discovered to be one of the Nanomaterials with an exceptional variety of characteristics with the potential to improve the strength and toughness of cement-based composites. Nano-material concrete is a new kind of concrete composed of materials with Nano scale particle sizes. Graphene Oxide can be used in concrete to create high strength concrete. The mix design was calculated for M80 by substituting 15\% cement with Fly Ash and another 15\% cement with Ground Granulated Blast Furnace Slag (GGBS or GGBFS) to get High Strength Self-Compacting Concrete (HSSCC). In this paper, Graphene Oxide was added in $0 \%, 0.02 \%, 0.04 \%, 0.06 \%, 0.08 \%$ and $0.1 \%$ by weight of powder content to the Self Compacting Concrete. Fresh properties were determined by performing Slump Flow test, V-Funnel test, and L-Box test. Hardened properties were determined by conducting compression test, split tensile test and flexural test at 7 days and 28 days of age. By inclusion of Graphene Oxide to the self-compacting concrete, desired properties were achieved.

Keywords: Graphene Oxide, Fly ash, Ground Granulated Blast Furnace Slag, High Strength Self Compacting Concrete.

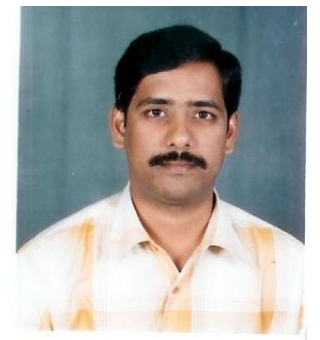

B. Narendra Kumar, received his B.Tech in Civil Engineering, M.Tech in Structural Engineering and Ph.D in Structural Engineering at JNTU, Hyderabad. Presently, he is a Professor in Department of Civil Engineering, VNR Vignana Jyothi Institute of Engineering \& Technology, Hyderabad. His research interests are SCC, special concretes, structural health monitoring and concrete mix designs. He has guided 22 M.Tech projects and delivered invited lectures in other organizations.

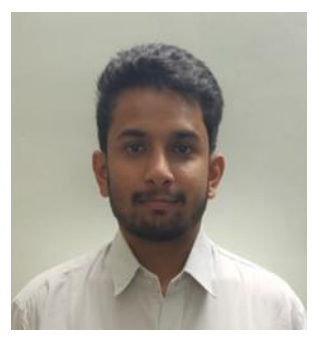

B. Abhilash is currently pursuing his B.Tech final year in Department of Civil Engineering from VNR Vignana Jyothi Institute Of Engineering \& Technology, Hyderabad. His research interests are SCC and concrete mix designs.

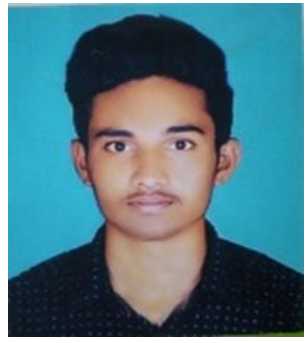

Ch. Naveen Kumar is currently pursuing his B.Tech final year in Department of Civil Engineering from VNR Vignana Jyothi Institute Of Engineering \& Technology, Hyderabad. His research interests are SCC and concrete mix designs.

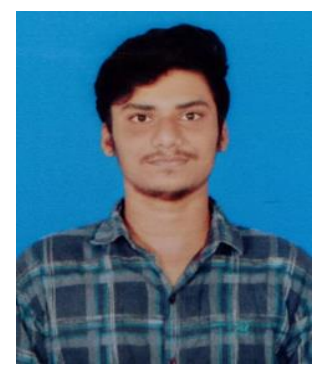

S. Pavan is currently pursuing his B.Tech final year in Department of Civil Engineering from VNR Vignana Jyothi Institute Of Engineering \& Technology, Hyderabad. His research interests are SCC and concrete mix designs. 


\section{Introduction}

Concrete is the most widely utilized man-made material on the planet [1]. The usage of concrete has rapidly increased in the construction field. Cement is used as binding material in the preparation of concrete [2]. Concrete hardens to form a rock-like massive substance. It is composed of components like fine aggregate and coarse aggregate that are held together by a cementitious ingredient like cement [3].

Concrete is a key building material that is widely utilized in the construction of buildings, bridges, highways, and dams [4]. Its applications range from structural to kerbs, pipelines, and sewers. It has various advantages since it is a very abundant manmade material that has a relatively long life with low maintenance requirements and is rigorous under compression [5]. It is a very pliable substance that can be readily moulded before it solidifies, and it is noncombustible [6].

The selection of concrete proportions requires a balance between economy and needs for strength, durability, density, and aesthetics. Strength of concrete determines its quality [7]. The strength of concrete increases with age until it reaches a maximum. There are mainly three types of concrete grades: regular grade, standard grade, and high strength concrete grade [8]. M5, M7.5, M10, M15 and M20 are regular concrete grades, M25, M30, M35, M40 and M45 are standard concrete grades, while M50, M55, M60, M65 and $\mathrm{M70}$ are higher strength concrete grades. Based on requirements of construction, the type of concrete mix is selected.

As a result of the many challenges encountered in the area of construction due to conventional concrete, which requires mechanical vibrators to eliminate gaps and occupy the whole shuttering area, the Self Compacting Concrete was created to overcome these obstacles [9].

The Self Compacting Concrete is a special type of concrete which has tendency to compact itself by its own weight [7]. Due to self-compaction property, the concrete can reach each and every corner of the form work in heavy reinforcement construction sites to reduce the labor and machinery cost by removing the vibration process. It was first started in Japan [10].

In general, Self-Compacting Concrete is made using the mix design procedures defined in IS 10262:2019 for all conventional concrete types [3]. Once the mix design is completed, tests on the fresh and hardened properties of the concrete are performed to determine whether the concrete met the design characteristics or not.

According to IS 1199 Part-6, if the concrete mix satisfies the below mentioned characteristics, then only it can be classified as Self Compacting Concrete.

Flowability, Passability, Segregation resistance, and Viscosity.

Nano materials are described as compounds with particle sizes less than $100 \mathrm{~nm}$. Unique characteristics are developed at this size, and these features have the potential to make significant implications in medical, electronics, construction and some other sectors [5]. Nano materials like Graphene oxide, Nano silica, Fullerenes, Carbon nano tubes, etc [11]. are used in construction sector. Some of the studies have demonstrated that the incorporation of nano materials can significantly improve the properties of ordinary Portland cement paste [12]. In this project, the effect of Graphene Oxide on the physical properties of Self Compacting Concrete are experimentally investigated.

\section{Materials Required}

The materials required for HSSCC are mentioned in below Table 1 .

Table 1. Materials required for HSSCC

\begin{tabular}{|c|c|}
\hline Binder & $\begin{array}{c}\text { Cement, Fly ash and } \\
\text { GGBS }\end{array}$ \\
\hline Nano material & Graphene Oxide \\
\hline Fine Aggregate & River Sand \\
\hline Coarse Aggregate & Gravel \\
\hline Super Plasticizer & Master Glenium ACE30 \\
\hline Hardener & Water \\
\hline
\end{tabular}

\section{Development of Mix Proportions of Hsscc}

\subsection{Mix Proportions}

The mix proportions HSSCC1-HSSCC6 shows the inclusion of Graphene Oxide in $0 \%, 0.02 \%, 0.04 \%$, $0.06 \%, 0.08 \%$ and $0.1 \%$ of powder content. The mix designations are shown in Table 2.

\subsection{Fresh Properties}

As per EFNARC guidelines, the mix designations obtained are examined for fresh properties (Figure 1,2 and 3). Table 3 shows the fresh properties of HSSCC in full detail. The variation of fresh properties of each mix is depicted in figures 4,5 and 6. 
Table 2. Mix Proportions of HSSCC

\begin{tabular}{|r|r|r|r|r|l|r|r|r|}
\hline $\begin{array}{l}\text { Mix } \\
\text { Designation }\end{array}$ & $\begin{array}{r}\text { Cement } \\
\left(\mathrm{kg} / \mathrm{m}^{3}\right)\end{array}$ & $\begin{array}{l}\text { Fly Ash } \\
\left(\mathrm{kg} / \mathrm{m}^{3}\right)\end{array}$ & $\begin{array}{l}\text { GGBS } \\
\left(\mathrm{kg} / \mathrm{m}^{3}\right)\end{array}$ & $\begin{array}{l}\text { Fine } \\
\text { aggregate } \\
\left(\mathrm{kg} / \mathrm{m}^{3}\right)\end{array}$ & $\begin{array}{l}\text { Coarseaggregate } \\
\left(\mathrm{kg} / \mathrm{m}^{3}\right)\end{array}$ & $\begin{array}{l}\text { SP } \\
\left(\mathrm{kg} / \mathrm{m}^{3}\right)\end{array}$ & $\begin{array}{l}\text { GO\% of } \\
\text { powder } \\
\text { content }\end{array}$ & $\begin{array}{l}\text { W/P } \\
\text { ratio }\end{array}$ \\
\hline HSSCC 1 & 500 & 105 & 105 & 840 & 780 & 5.6 & 0 & 0.28 \\
\hline HSSCC 2 & 500 & 105 & 105 & 840 & 840 & 5.6 & 0.02 & 0.28 \\
\hline HSSCC 3 & 500 & 105 & 105 & 840 & 840 & 5.6 & 0.04 & 0.28 \\
\hline HSSCC 4 & 500 & 105 & 105 & 840 & 840 & 5.6 & 0.06 & 0.28 \\
\hline HSSCC 5 & 500 & 105 & 105 & 840 & 840 & 5.6 & 0.08 & 0.28 \\
\hline HSSCC 6 & 500 & 105 & 105 & 840 & 840 & 5.6 & 0.1 & 0.28 \\
\hline
\end{tabular}

Table 3. Fresh Properties of HSSCC

\begin{tabular}{|c|c|c|c|c|c|}
\hline \multirow{2}{*}{$\begin{array}{c}\text { Mix } \\
\text { Designation }\end{array}$} & \multicolumn{2}{|c|}{ Flow Table } & \multicolumn{2}{|c|}{ V Funnel } & \multirow{2}{*}{$\begin{array}{l}\text { L-box } \\
\text { ratios }\end{array}$} \\
\hline & $\begin{array}{c}\text { Diameter } \\
(\mathrm{mm})\end{array}$ & $T_{50}$ (seconds) & $T_{f}$ (seconds) & $\mathrm{T}_{5 \mathrm{~min}}$ (seconds) & \\
\hline HSSCC 1 & 700 & 3.0 & 6.0 & 7.0 & 0.88 \\
\hline HSSCC 2 & 680 & 3.0 & 7.0 & 9.0 & 0.88 \\
\hline HSSCC 3 & 650 & 4.0 & 8.0 & 10.0 & 0.87 \\
\hline HSSCC 4 & 610 & 4.0 & 9.0 & 11.0 & 0.83 \\
\hline HSSCC 5 & 600 & 5.0 & 9.0 & 11.0 & 0.84 \\
\hline HSSCC 6 & 590 & 6.0 & 10.0 & 12.0 & 0.80 \\
\hline
\end{tabular}

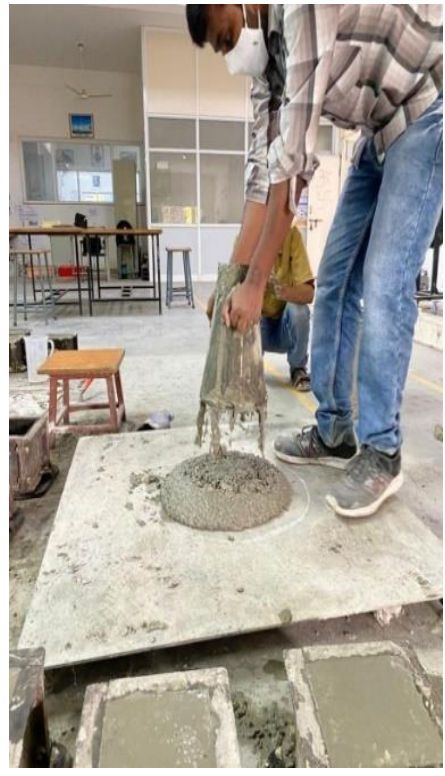

Figure 1. Performing Slump flow Test

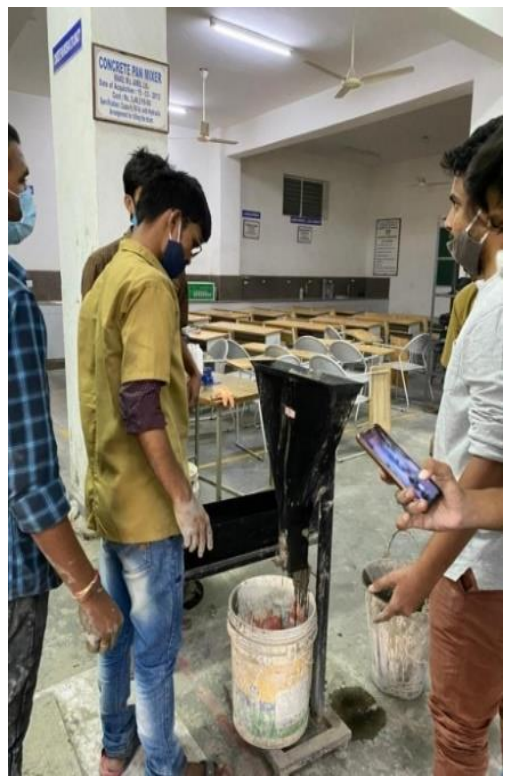

Figure 2. Performing VFunnel Test

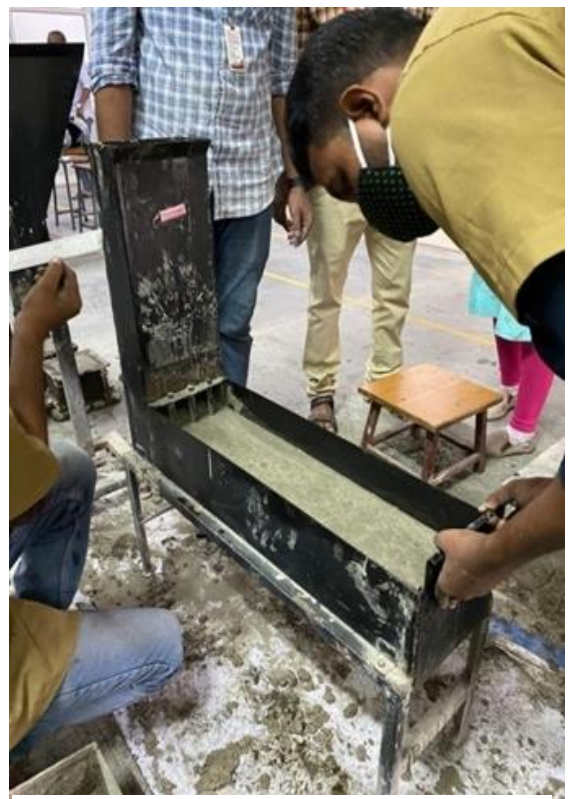

Figure 3. Performing L-Box Test 


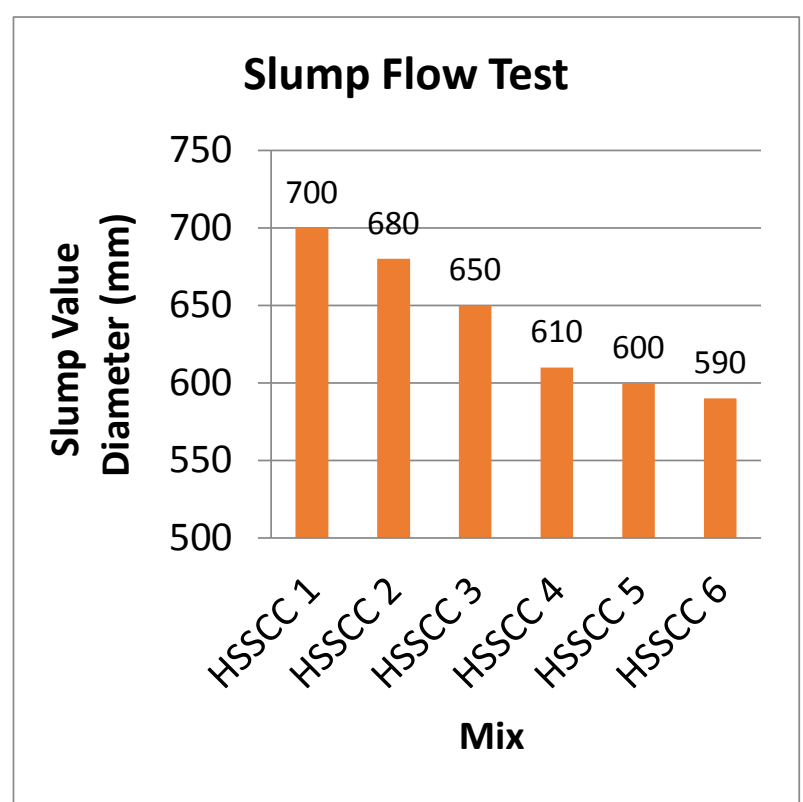

Figure 4. Graphical Representation of Slump Flow Test Values

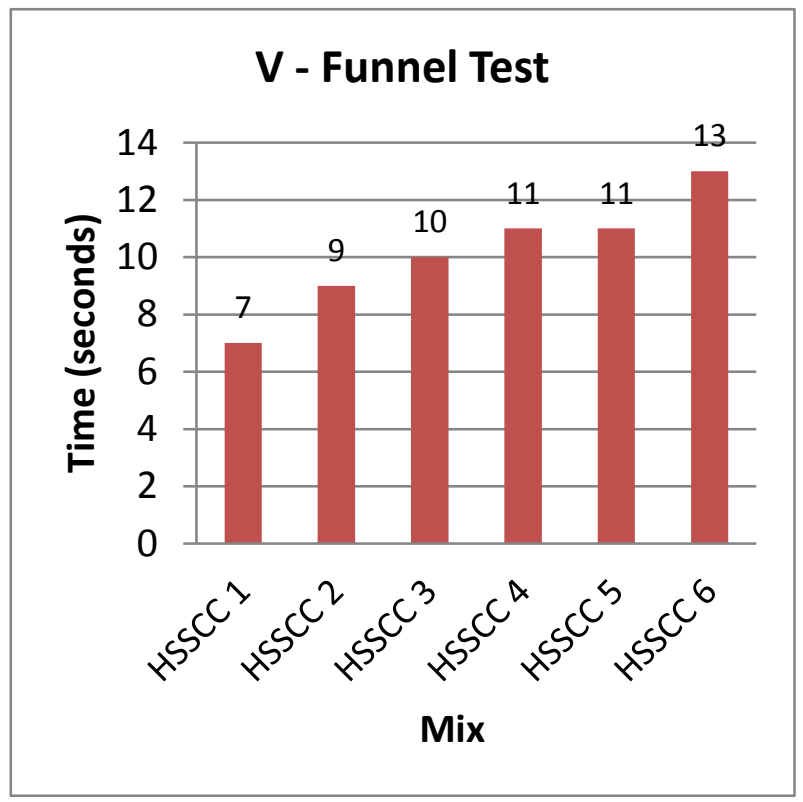

Figure 5. Graphical Representation of VFunnel Test Values

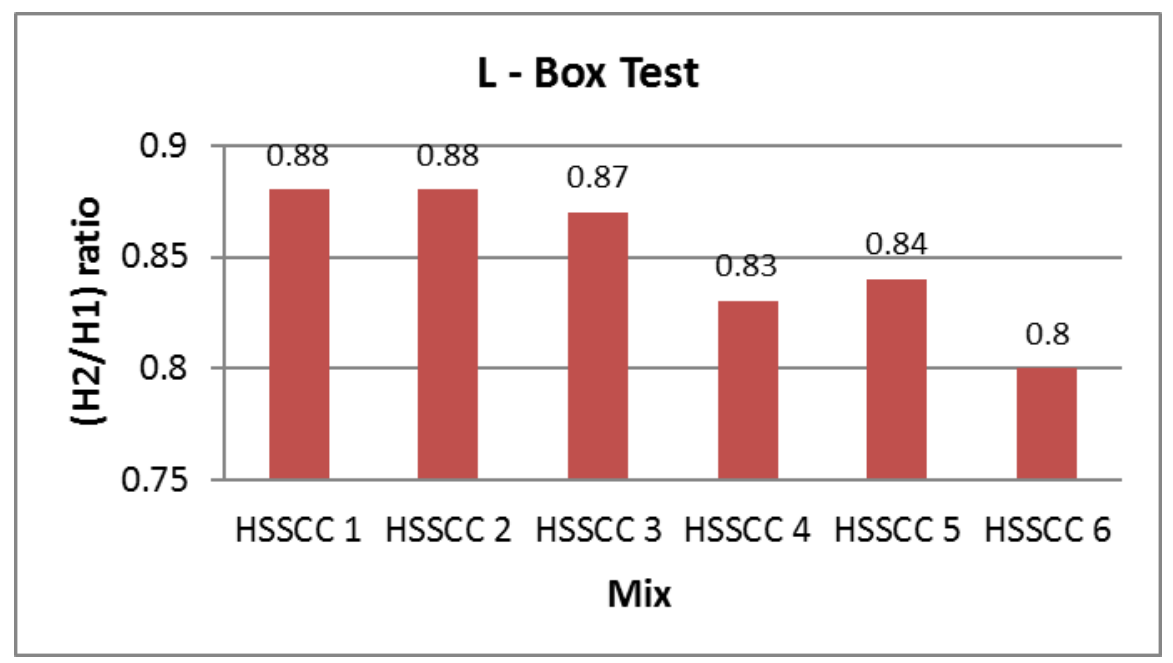

Figure 6. Graphical Representation of L - Box Test Values

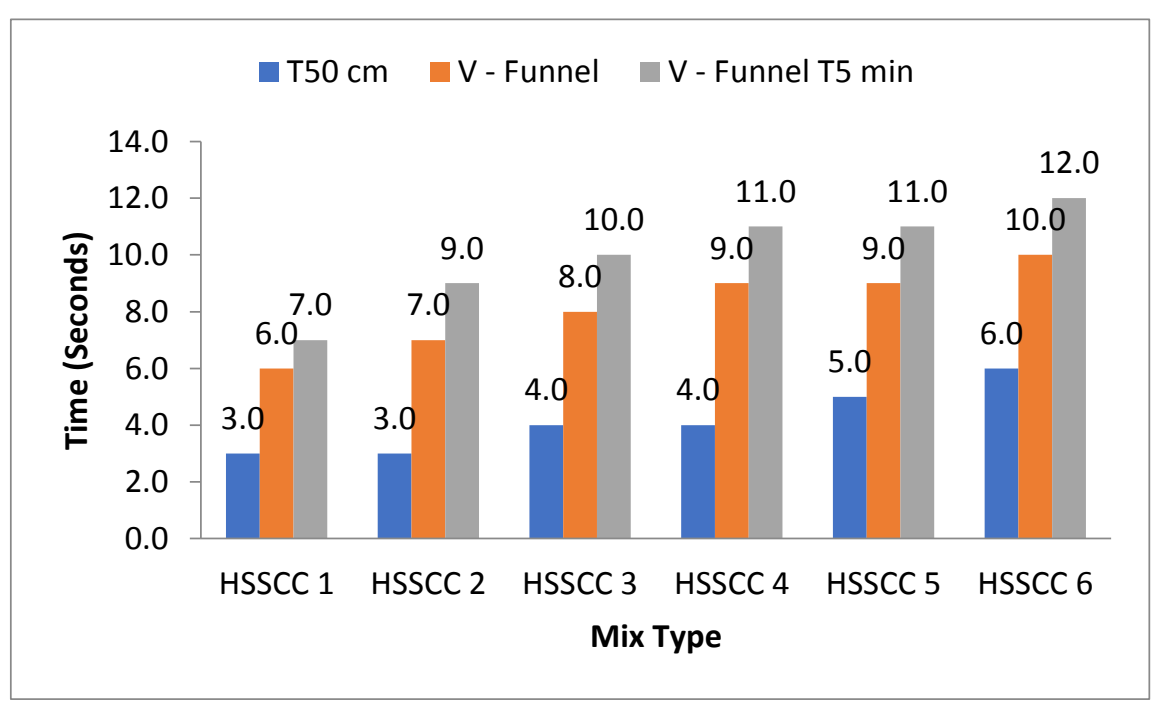

Figure 7. Variation of $T_{50 \mathrm{~cm}}$, V-Funnel and V-Funnel $T_{5 \min }$ for HSSCC 


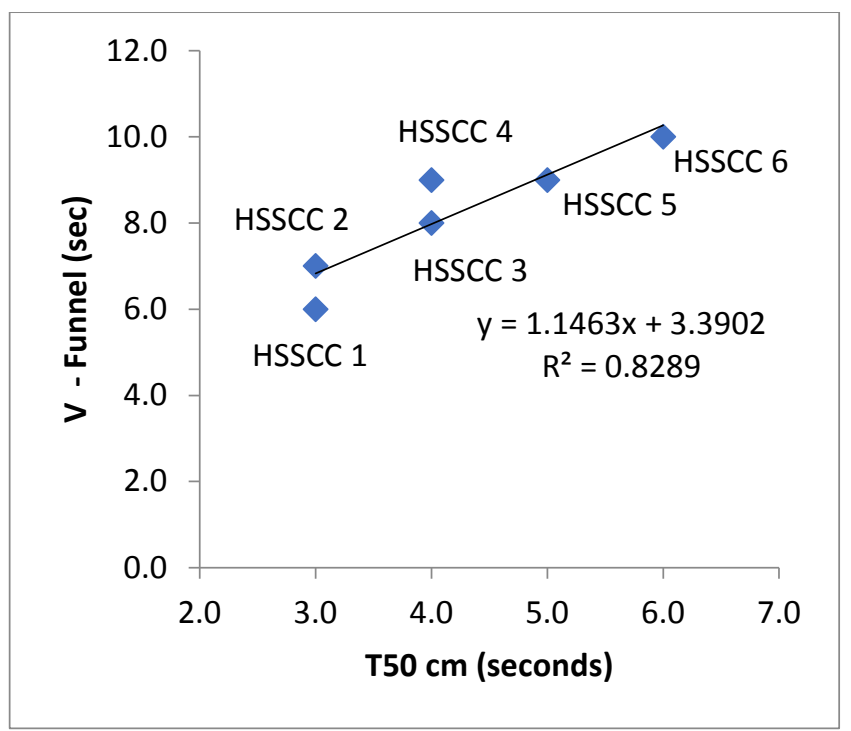

Figure 8. Graph of Slump flow vs $T_{50 \mathrm{~cm}}$

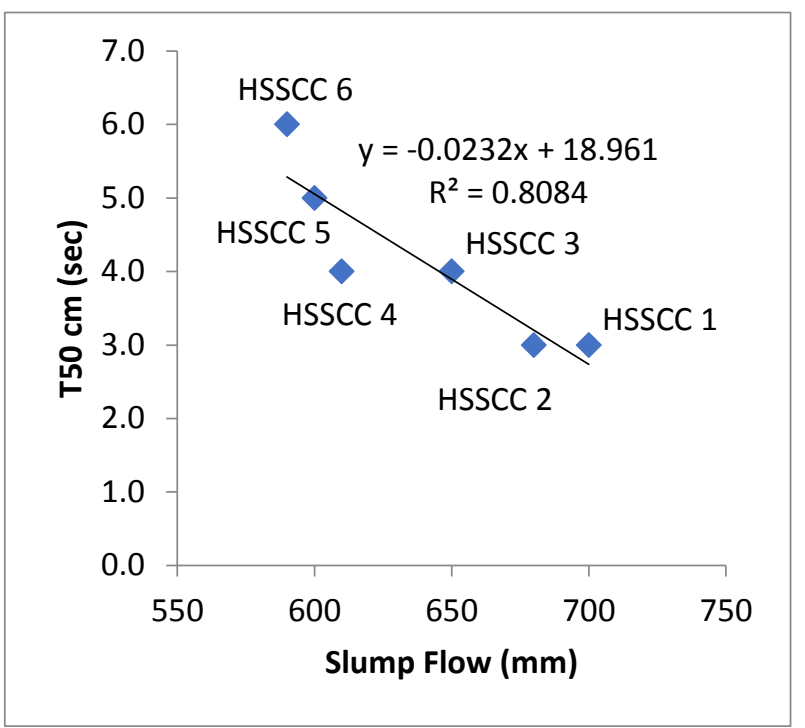

Figure 9. Graph of T50cm vs V -funnel for HSSCC

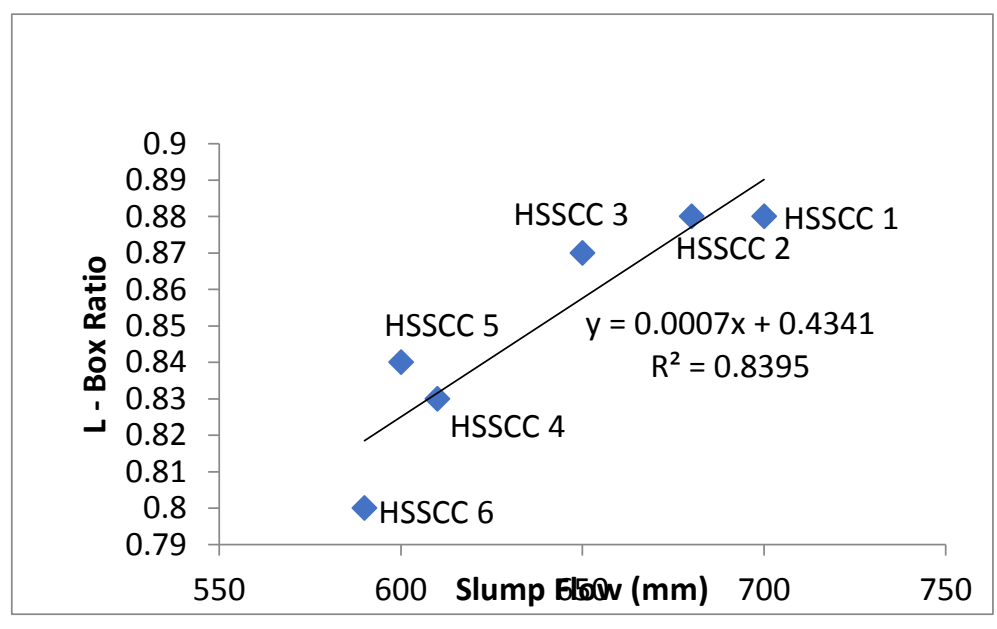

Figure 10. Graph of Slump flow vs L-Box for HSSCC

\section{Hardened Properties}

\subsection{Compressive strength}

Compression strength is one of the most important hardened properties of concrete. This test is conducted on the cubes of size $150 \mathrm{~mm} \times 150 \mathrm{~mm}$ $x 150 \mathrm{~mm}$ and these cubes are tested uni-axially under testing machine. Load is uniformly applied on the specimen. This testing was conducted on the specimens at 7days and 28days of curing. In the Table 4 compressive strength values of HSSCC1-HSSCC6 are presented.

\subsection{Split Tensile Strength}

In this test, the shear resistance offered by the concrete is determined. The strength is measured using a cylindrical specimen with a diameter of 150 $\mathrm{mm}$ and a height of $300 \mathrm{~mm}$. The specimen is subjected to a load until it fails. This test is also performed at 7days and 28days of curing. In the Table 5 compressive strength values of HSSCC1-HSSCC6 are presented.

\subsection{Flexure Strength}

The flexure strength of a specimen of size 100 $\mathrm{mm} \times 100 \mathrm{~mm} \times 500 \mathrm{~mm}$ is evaluated in this test. The flexure strength of concrete can be conducted by two types of methods namely Three-point load method and Centre point load method. Here, Three-point load method is opted for the specimens. The load is applied on the specimens until it breaks. In the Table 6 compressive strength values of HSSCC1-HSSCC6 are presented. 
Table 4. Compression Strength of HSSCC

\begin{tabular}{|c|c|c|}
\hline Mix & Compressive Strength for 7 days in MPa & $\begin{array}{c}\text { Compressive Strength for } \\
\text { 28 days in MPa }\end{array}$ \\
\hline HSSCC 1 & 64.2 & 71.4 \\
\hline HSSCC 2 & 69.6 & 73.2 \\
\hline HSSCC 3 & 76.8 & 79.8 \\
\hline HSSCC 4 & 80.4 & 84.92 \\
\hline HSSCC 5 & 82.8 & 86.4 \\
\hline HSSCC 6 & 84.5 & 89.2 \\
\hline
\end{tabular}

\section{Compressive Strength for $\mathbf{2 8}$ days}

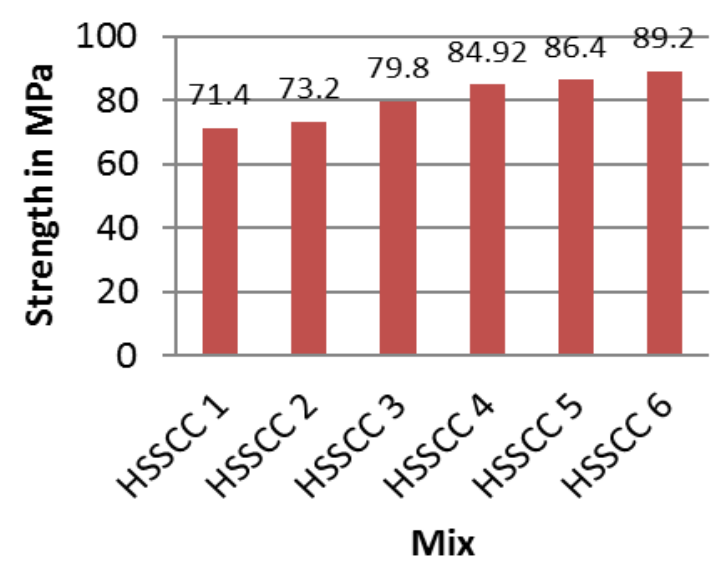

Figure 11. Graphical Representation of Compression Test values for 7 days

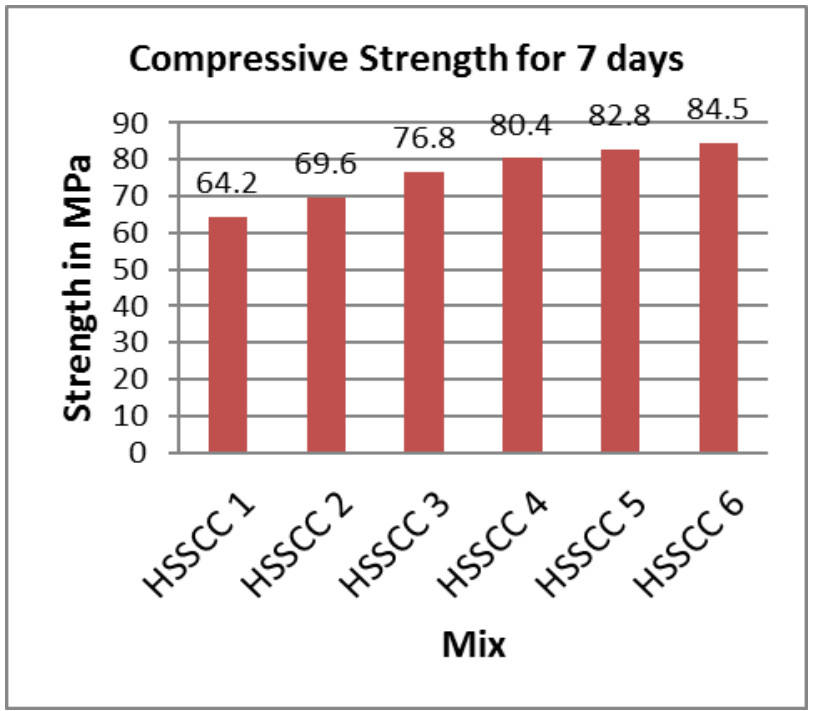

Figure 12. Graphical Representation of Compression Test values for 28 days days

Table 5. Split Tensile Strength of HSSCC

\begin{tabular}{|c|c|c|}
\hline Mix & $\begin{array}{c}\text { Split Tensile Strength for } \mathbf{7} \text { days in } \\
\mathbf{M P a}\end{array}$ & $\begin{array}{c}\text { Split Tensile Strength for 28 } \\
\text { days in } \mathbf{~ P a}\end{array}$ \\
\hline HSSCC 1 & 5.14 & 7.14 \\
\hline HSSCC 2 & 9.74 & 13.18 \\
\hline HSSCC 3 & 12.29 & 15.96 \\
\hline HSSCC 4 & 14.47 & 17.83 \\
\hline HSSCC 5 & 14.9 & 18.14 \\
\hline HSSCC 6 & 16.9 & 20.65 \\
\hline
\end{tabular}

Table 6. Flexure Strength of HSSCC

\begin{tabular}{|c|c|c|}
\hline Mix & $\begin{array}{c}\text { Flexure Strength for 7 days in } \\
\mathbf{M P a}\end{array}$ & $\begin{array}{c}\text { Flexure Strength for 28 } \\
\text { days in } \mathbf{M P a}\end{array}$ \\
\hline HSSCC 1 & 6.42 & 8.57 \\
\hline HSSCC 2 & 11.14 & 14.64 \\
\hline HSSCC 3 & 13.82 & 15.96 \\
\hline HSSCC 4 & 15.28 & 18.68 \\
\hline HSSCC 5 & 15.73 & 19.01 \\
\hline HSSCC 6 & 16.28 & 20.43 \\
\hline
\end{tabular}




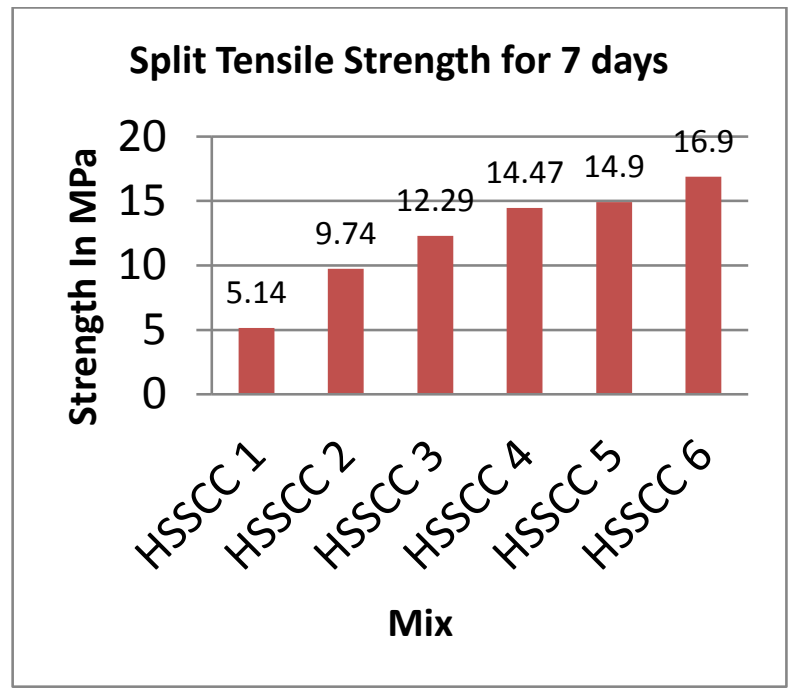

Figure 13. Graphical Representation of Split Tensile Test Values for 7 days for 7

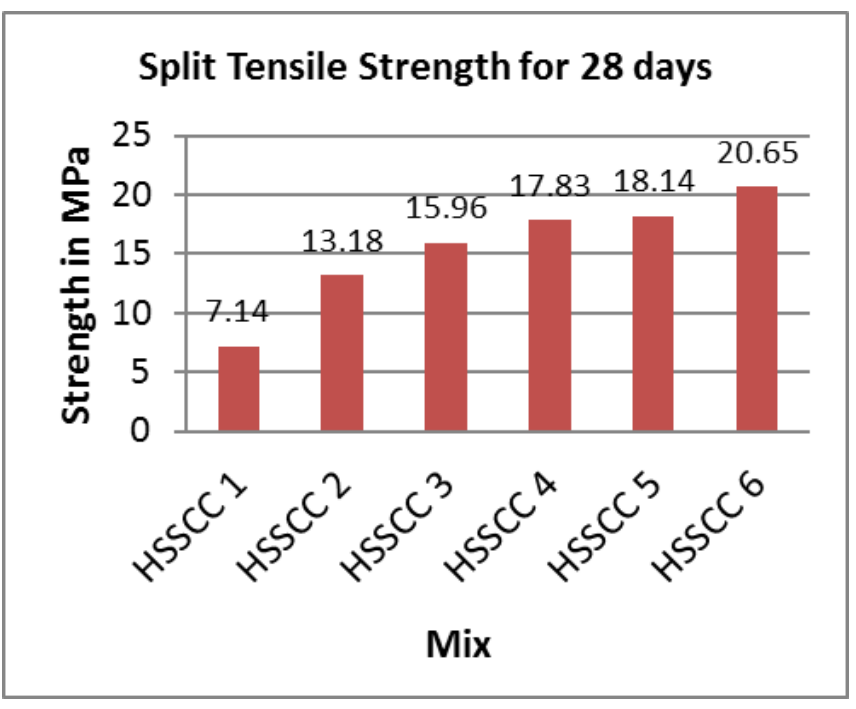

Figure 14. Graphical Representation of Split Tensile Test values for 28 days

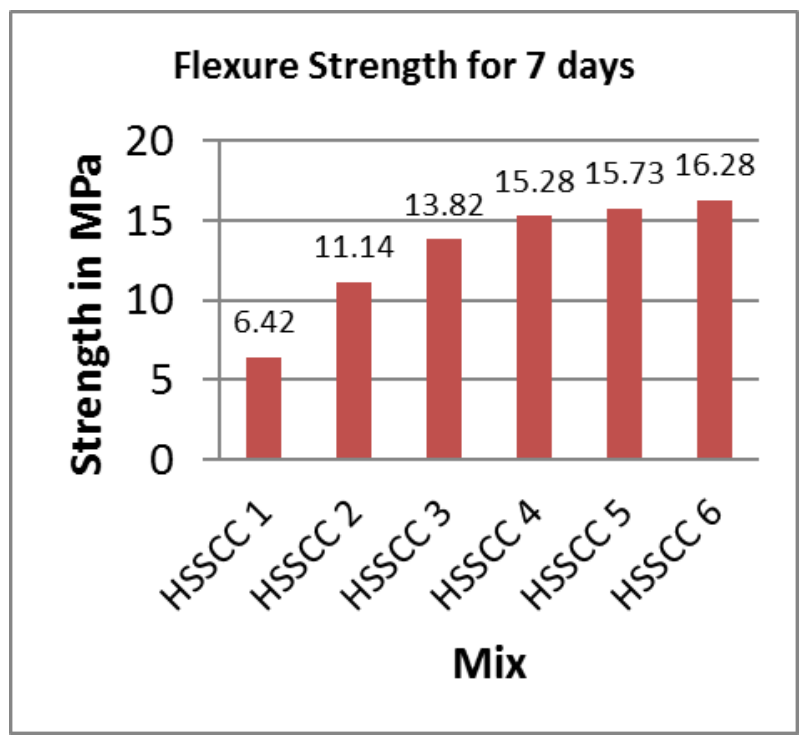

Figure 15. Graphical Representation of Flexure Test Values for 7 days

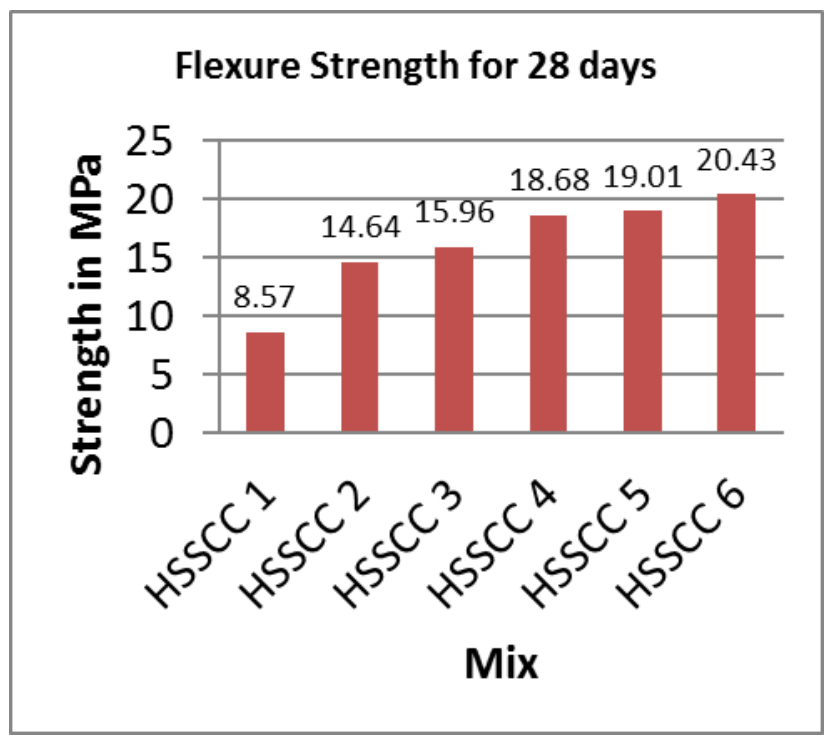

Figure 16. Graphical Representation of Flexural Test values for 28 days 


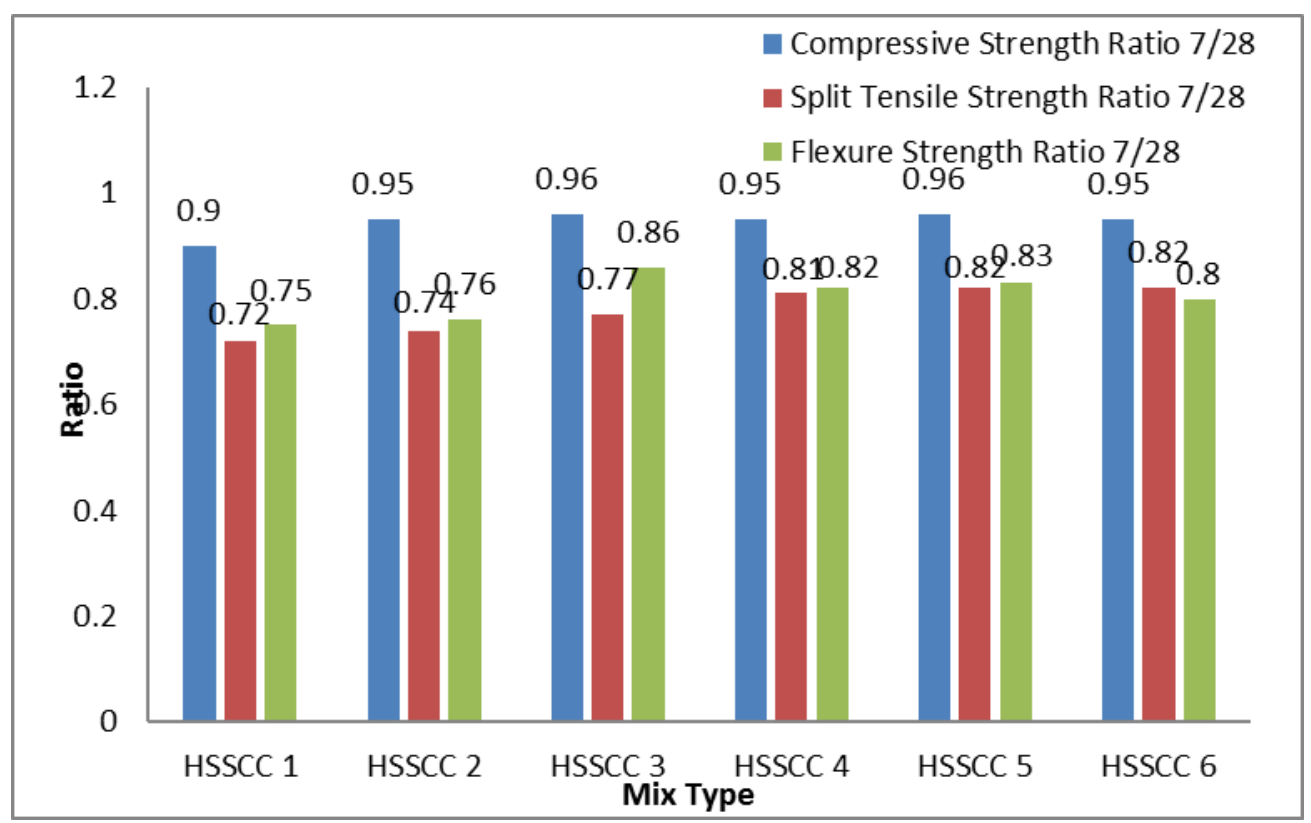

Figure 17. Plot of strength ratios of HSSCC

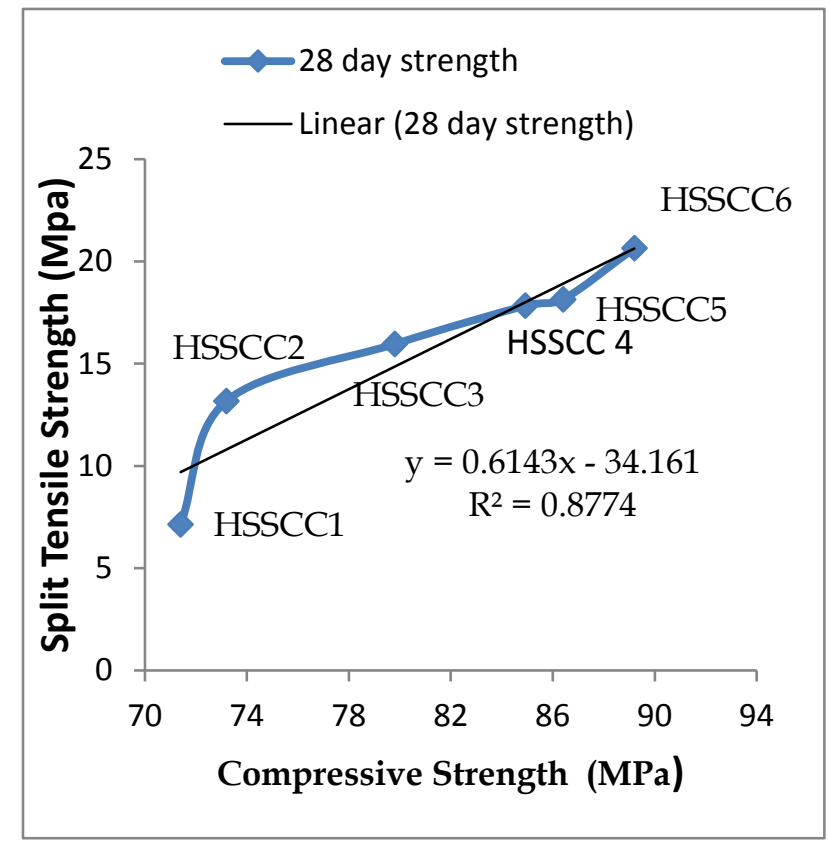

Figure 18. Graph of Split Tensile strength Vs Compressive strength of HSSCC

\section{Discussion of Result}

The results obtained in the experimental investigation of inclusion of GO into the HSSCC.

\subsection{Fresh Properties}

As mentioned previously, the presence of graphene oxide correlates with HSSCC1-HSSCC6. Table 1 illustrates the mix proportions in detail and Table 2 illustrates the fresh properties. Graphs of the variations

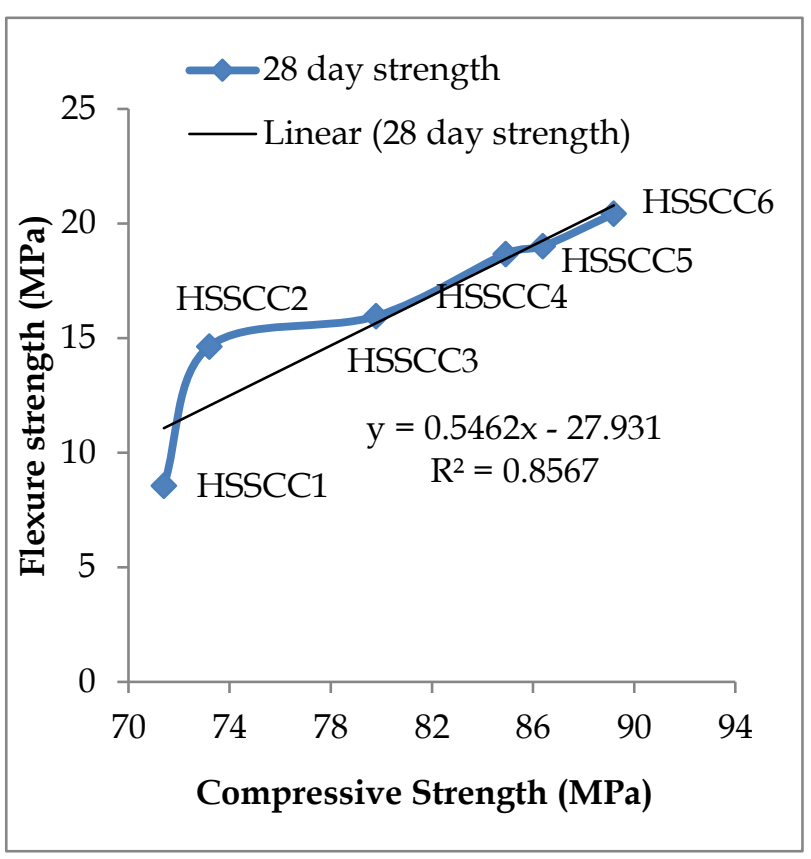

Figure 19. Graph of Flexural strength Vs Compression strength of HSSCC

of several fresh properties for different dosages of graphene oxide inclusion are shown in Figure 4-6.

It is clearly observed that with the increase in the percentage of graphene oxide to the selfcompacting concrete, there is considerable decrease in the fresh properties as shown in table 2 and figures 46. Moreover, the mixes HSSCC 1 to HSSCC 6 were satisfying the EFNARC specifications.

Figure 7 shows the variation of fresh properties by inclusion of graphene oxide considering time as a 
parameter for the mixes HSSCC 1 to HSSCC 6. Plots of comparison of various fresh properties are represented in the figures 8,9 and 10 .

\subsection{Compressive Strength}

The compressive strength values at 7 days and 28 days for the mixes HSSCC1-HSSCC6 are shown in Table 4, in which the dosage of graphene oxide is varied for each mix. Figures 11 and 12 show the variation in concrete compressive strength from 7 to 28 days for various mix designations.

It can be shown that all of the mixes had a significant initial strength gain at an early age. The maximum compressive strength was observed for the mix containing $0.1 \%$ graphene oxide. There is an increase in the compressive strength of about $31.6 \%$ and $24.9 \%$ for 7 days and 28 days of age respectively.

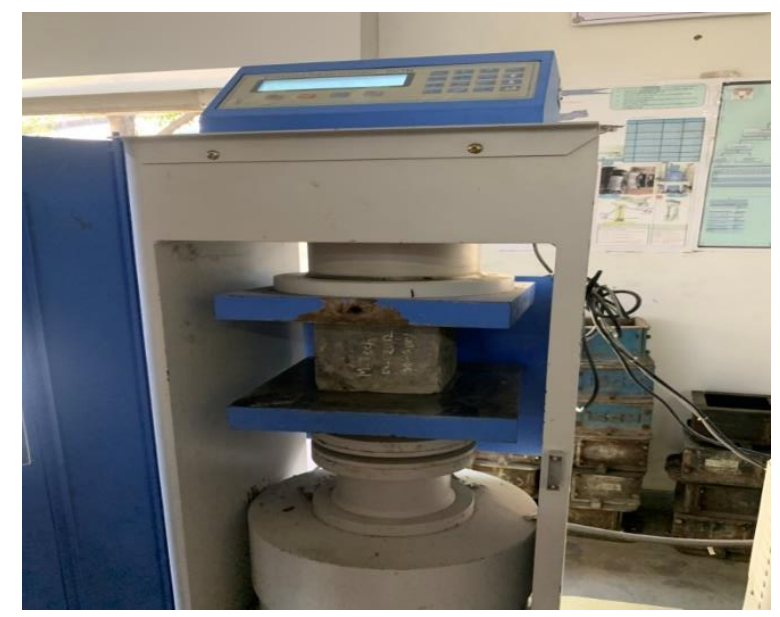

Figure 20. Compression Test

\subsection{Split Tensile Strength}

The split tensile strength values at 7 days and 28 days for the mixes HSSCC 1 to HSSCC 6 in which the dosages of graphene oxide are varied are shown in Table 5. Figure 13 and 14 represents the variation of split tensile strength for different mixes at 7 days to 28 days.

It can be observed that the mix containing $0.1 \%$ graphene oxide has the maximum split tensile value. In figure 18, a typical plot relationship was drawn from the compressive strength and the split tensile strength values. It can be noted that the slope of the plot is positive due to increasing content of graphene oxide. The split tensile strength is approximately $8-15$ percent of the compressive strength.

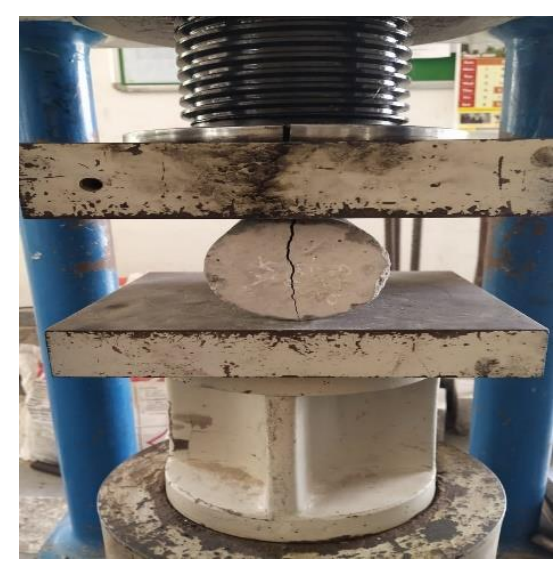

Figure 21. Split Tensile Test

\subsection{Flexure Strength}

The flexure strength values at 7 days and 28 days for the mixes HSSCC 1 to HSSCC 6 in which percentage of graphene oxide is varied for each mix as shown in Table 6. Figure 11 and 19 represents the variation of flexure strength for various mixes for 7 days to 28 days. The compression, split tensile and flexure instruments are shown in figure 20-22.

It can be observed that the mix containing $0.1 \%$ graphene oxide has the maximum flexure strength value. For both 7 and 28 days of age, there is a 58-64 percent increase in flexure strength, respectively. In figure 19 , a typical plot relationship was drawn from the compressive strength and the flexure strength values. It can be noted that the slope of the plot is positive due to increasing content of graphene oxide. The flexure strength is approximately 10-18 percent of the compressive strength.

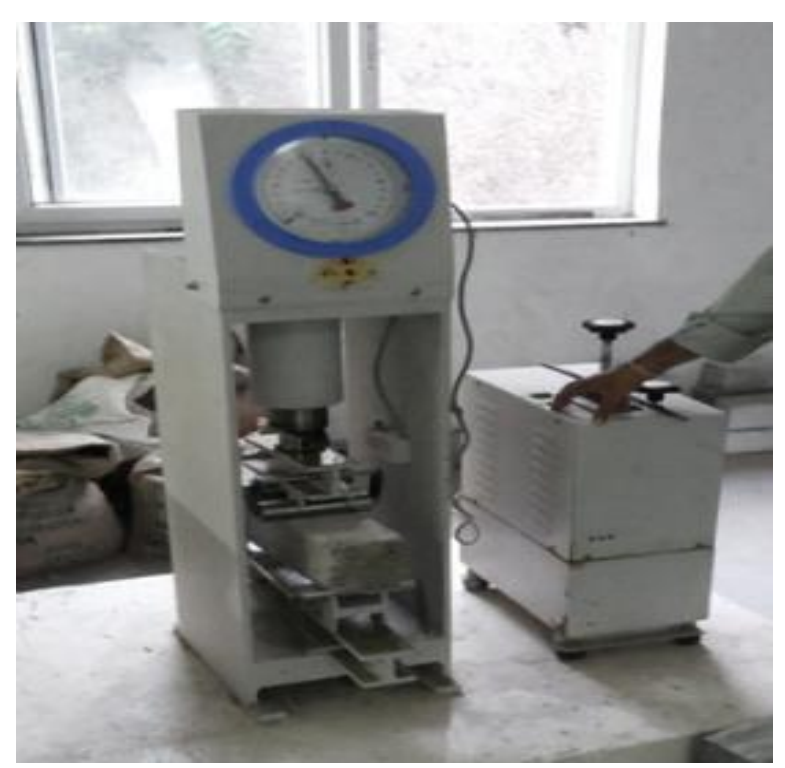

Figure 22. Flexure Test 


\section{Conclusions}

From the above test results the following conclusions were made.

- During the casting of concrete specimens, the workability of the Self Compacting Concrete (SCC) should be controlled carefully. Graphene oxide absorbed more water and lowered the workability because of its greater surface area.

- The use of a super plasticizer aided in the restoration of workability.

- The maximum compressive strength of $89.2 \mathrm{MPa}$, the maximum split tensile strength of $20.65 \mathrm{MPa}$ and the maximum flexure strength of $20.43 \mathrm{MPa}$ were obtained by adding $0.1 \%$ of graphene oxide containing concrete.

- At 28 days of curing, compressive, split tensile, and flexural strength were improved when graphene oxide was incorporated to the High Strength Self Compacting M80 Concrete.

\section{References}

[1] L. Lu, P. Zhao, Z. Lu, A short discussion on how to effectively use graphene oxide to reinforce cementitious composites, Construction and Building Materials, 189 (2018) 33-41. [DOI]

[2] Y. Shang, D. Zhang, C. Yang, Y. Liu, Y. Liu, Effect of graphene oxide on the rheological properties of cement pastes. Construction and Building Materials, 96 (2015) 20-28. [DOI]

[3] X. Li, C. Li, Y. Liu, S. J. Chen, C. M. Wang, J. G. Sanjayan, W.H. Duan, Improvement of mechanical properties by incorporating graphene oxide into cement mortar. Mechanics of Advanced Materials and Structures, 25 (2018) 1313-1322. [DOI]

[4] S.C. Devi, R.A. Khan, Effect of graphene oxide on mechanical and durability performance of concrete. Journal of Building Engineering, 27 (2020) 101007. [DOI]

[5] A. Mohammed, J.G. Sanjayan, A. Nazari, N.T.K. Al-Saadi, Effects of graphene oxide in enhancing the performance of concrete exposed to high temperature, Australian Journal of Civil Engineering, 15 (2017) 61-71. [DOI]

[6] F. Babak, H. Abolfazl, R. Alimorad, G. Parviz, (2014) Preparation and mechanical properties of graphene oxide: cement nanocomposites,
The Scientific World Journal, 2014 (2014) 1-11. [DOI]

[7] M. Chen, L. Li, Y. Zheng, P. Zhao, L. Lu, X. Cheng, Rheological and mechanical properties of admixtures modified 3D printing sulphoaluminate cementitious materials, Construction and Building Materials, 189 (2018) 601-611. [DOI]

[8] J. Liu, J. Fu, Y. Yang, C. Gu, Study on dispersion, mechanical and microstructure properties of cement paste incorporating graphene sheets, Construction and Building Materials, 199 (2019) 1-11. [DOI]

[9] C.S.R. Indukuri, R. Nerella, S.R.C. Madduru, Effect of graphene oxide on microstructure and strengthened properties of fly ash and silica fume-based cement composites, Construction and Building Materials, 229 (2019) 116863. [DOI]

[10] A. Mohammed, N.T.K. Al-Saadi, J. Sanjayan, Inclusion of graphene oxide in cementitious composites: state-of-the-art review, Australian Journal of Civil Engineering, 16 (2018) 81-95. [DOI]

[11] A. Mohammed, J. G. Sanjayan, A. Nazari, N.T.K. Al-Saadi, Effects of graphene oxide in enhancing the performance of concrete exposed to high temperature, Australian Journal of Civil Engineering, 15 (2017) 61-71. [DOI]

[12] A. Mohammed, J. G. Sanjayan, W.H. Duan, A. Nazari, Incorporating graphene oxide in cement composites: A study of transport properties, Construction and Building Materials, 84 (2015) 341-347. [DOI]

\section{Funding}

No funding was received for conducting this study.

\section{Does this article screened for similarity? Yes}

\section{Conflict of interest}

The authors have no conflicts of interest to declare that they are relevant to the content of this article.

\section{About the License}

(C) The author(s) 2021. The text of this article is open access and licensed under a Creative Commons Attribution 4.0 International License 